\title{
Effort Application in an Arranged Marriage: A Game-Theoretic Analysis
}

\author{
Amitrajeet A. Batabyal' ${ }^{1}$, Seung Jick Yoo ${ }^{2 *}$ \\ ${ }^{1}$ Department of Economics, Rochester Institute of Technology, Rochester, NY, USA \\ ${ }^{2}$ Graduate School of International Service, Sookmyung Women's University, Seoul, Republic of Korea \\ Email: aabgsh@rit.edu, *sjyoo@sookmyung.ac.kr
}

How to cite this paper: Batabyal, A.A. and Yoo, S.J. (2017) Effort Application in an Arranged Marriage: A Game-Theoretic Analysis. Theoretical Economics Letters, 7, 23-29.

http://dx.doi.org/10.4236/tel.2017.71003

Received: October 13, 2016

Accepted: December 9, 2016

Published: December 14, 2016

Copyright $\odot 2017$ by authors and Scientific Research Publishing Inc. This work is licensed under the Creative Commons Attribution International License (CC BY 4.0).

http://creativecommons.org/licenses/by/4.0/

\section{(c) (i) Open Access}

\begin{abstract}
In this note we study a simple game model of effort application by two individuals ( 1 and 2) who wish to have an arranged marriage. We first specify the net utility function of individual $i$ as a function of this individual's own effort and the effort applied by individual $j, i \neq j$, in three distinct cases. Next, we compute the ith individual's best response function. Finally, we analyze effort application by two identical pairs of individuals who are located in two different nations. In the first (second) nation, arranged marriages are uncommon (common) and hence it is relatively difficult (straightforward) for the two individuals to apply and coordinate effort. We explain why the net utility of the pair wishing to have an arranged marriage in the first nation is likely to be much lower than the corresponding net utility of the pair in the second nation.
\end{abstract}

\section{Keywords}

Arranged Marriage, Effort, Net Utility, Static Game, Strategic Complements

\section{Introduction}

Marriages can be broadly divided into two types. In western style "love" marriages, the salience of the role played by parents, relatives, and matchmakers is either secondary or often negligible. In contrast, in eastern style "arranged" marriages, the significance of the role played by the above trinity of individuals is substantial. Now, beginning with the seminal work of Gary Becker [1], western style "love" marriages have been analyzed from a variety of perspectives by economists such as Manser and Brown [2], Peters [3], Cornelius [4], and Vaillant and Harrant [5]. These and other such studies have shed light on many different topics such as household decision making from a bargaining standpoint, informational constraints in marriage and divorce, the nexuses between search theory on the one hand and marriage and divorce on the other, and the activities of a French matchmaking agency. 
This notwithstanding, as Levine, Sato, Hashimoto, and Verma [6], Kumar and Dhyani [7], and others have noted, it is important to comprehend that "arranged" marriages are popular in many nations including, but not limited to, India, Pakistan, and Thailand. Even though arranged marriages are common in many parts of the world, the theoretical study of arranged marriages began only with Batabyal [8]. Since then, further work by Batabyal ([9], [10]), Liu [11], and Batabyal and Beladi [12] has examined several relevant issues such as the effect of a stochastic reservation quality level on decision making in arranged marriages, the determination of dowries in arranged marriages, and the ways in which stochastic dynamic programming can shed light on decision making in arranged marriages.

The studies mentioned in the previous paragraph have certainly advanced our understanding of several aspects of arranged marriages. Even so, to the best of our knowledge, with the exception of Batabyal [13], there are no studies of the nature and the implications of effort application by two individuals wishing to have an arranged marriage. The analysis in the Batabyal [13] paper is ex post in the sense that it conducts a game-theoretic examination of effort and time investment by two individuals who are already in an arranged marriage and would like to make this marriage work. In contrast, in this note we conduct an ex ante analysis of effort application by two individuals who wish to have an arranged marriage. In addition and unlike Batabyal [13], we analyze effort application by two identical pairs of individuals who are located in two different nations. In the first (second) nation, arranged marriages are uncommon (common) and hence it is relatively difficult (straightforward) for the two individuals to apply and coordinate effort.

The effort application problem in contemporary arranged marriages is salient because the two individuals wishing to get married in this way now have considerable autonomy. Therefore, as many commentators have noted, they are frequently involved in tasks such as the placement of newspaper advertisements, the placement of profiles in online matrimonial sites, information gathering and sharing with parents, relatives, and friends, and the hiring of one or more matchmakers ${ }^{1}$. This state of affairs explains why we concentrate on the ex ante effort application problem in the context of arranged marriages.

The remainder of this note is organized as follows. Section 2.1 describes the static game model of the effort applied by two individuals ( 1 and 2 ) who wish to have an arranged marriage. Section 2.2 specifies the net utility function of individual $i$ as a function of this individual's own effort and the effort applied by individual $j, i \neq j$, in three distinct cases. Section 2.3 computes the ith individual's best response function. Section 2.4 first analyzes effort application by two identical pairs of individuals who are located in two different nations. In the first (second) nation, arranged marriages are uncommon (common) and therefore it is relatively difficult (straightforward) for the two individuals to apply and coordinate effort. Next, in this setting, this section explains why the net utility of the pair wishing to have an arranged marriage in the first nation is likely to be much lower than the corresponding net utility of the pair in the second nation. Section 3 concludes and then suggests two ways in which the research in this note might be extended.

${ }^{1}$ See Uberoi [14], Lee [15], and Ravindra [16] for additional details on this point. 


\section{Analysis}

\subsection{The Game Model}

Consider two individuals ( 1 and 2 ) who wish to have an arranged marriage. Each individual $i$ can apply effort to make sure that the desired arranged marriage actually takes place. Note that effort here is a proxy for a variety of possible tasks that include, but are not limited to, the placement of newspaper advertisements and profiles in online matrimonial sites, information gathering and sharing with parents, relatives, and friends, and the hiring of one or more matchmakers. Let $e_{i} \geq 0$ denote the effort applied by individual $i$. We suppose that this effort is chosen from the closed set $[0,5]^{2}$.

Applying effort is costly to individual $i$ and therefore this application gives rise to disutility. This disutility can be described by the strictly convex function $d_{i}\left(e_{i}\right)=e_{i}^{2} / 4$. The reader may want to think of the effort $e_{i}$ as the number of hours required to either personally engage in or have others undertake one or more of the tasks delineated in the preceding paragraph.

The gross utility of each individual depends on both the effort applied by himself or herself and on the effort applied by the other individual. Specifically, if individuals $i$ and $j$ choose efforts $e_{i}$ and $e_{j}$ respectively then the gross utility to individual $i$ is given by

$$
U_{i}\left(e_{i}, e_{j}\right)=\left\{\begin{array}{ll}
0 & \text { if } e_{i}<1 \\
2 & \text { if } e_{i} \geq 1 \text { and } e_{j}<2 \\
e_{i} \cdot e_{j} & \text { if } e_{i} \geq 1 \text { and } e_{j} \geq 2
\end{array}\right\} .
$$

With this background out of the way, let us now stipulate the net utility function of individual $i$ as a function of his or her effort $e_{i}$ in three separate cases. Note that the net utility function is the difference between the gross utility and the disutility functions specified earlier in this section. In the first case $e_{j}<2$, in the second case $e_{j}=2$, and in the third case $e_{j}=4$.

\subsection{The Net Utility Function}

Some thought tells us that in the first case in which the $j t h$ individual's effort $e_{j}<2$, the net utility function of individual $i$ is

$$
u_{i}\left(e_{i}, e_{j}\right)=\left\{\begin{array}{ll}
0-e_{i}^{2} / 4 & \text { if } e_{i}<1 \\
2-e_{i}^{2} / 4 & \text { if } e_{i} \geq 1
\end{array}\right\} .
$$

Similarly, in the case where the $j$ th individual's effort $e_{j}=2$, the net utility function of individual $i$ is

$$
u_{i}\left(e_{i}, e_{j}\right)=\left\{\begin{array}{ll}
0-e_{i}^{2} / 4 & \text { if } e_{i}<1 \\
2 e_{i}-e_{i}^{2} / 4 & \text { if } e_{i} \geq 1
\end{array}\right\} .
$$

Finally, in the case where the $j$ th individual's effort $e_{j}=4$, the net utility function of individual $i$ is given by

$$
u_{i}\left(e_{i}, e_{j}\right)=\left\{\begin{array}{ll}
0-e_{i}^{2} / 4 & \text { if } e_{i}<1 \\
4 e_{i}-e_{i}^{2} / 4 & \text { if } e_{i} \geq 1
\end{array}\right\} .
$$

${ }^{2}$ Note that the choice of 5 as the upper limit of this set is without loss of generality. We use this specific value primarily to keep the subsequent mathematical analysis transparent. 
Inspecting the three net utility functions for individual $i$ given in Equations (2) through (4), we can immediately draw two unambiguous conclusions. First, in the effort range $e_{i} \in[0,1)$, the net utility for the $i t h$ individual is the same in all three cases. Second, in the effort range $e_{i} \in[1,5]$, the three net utility functions look very different. Specifically, in the $e_{j}<2$ case, the net utility function for individual $i$ slopes downward from the point $\left(e_{i}, e_{j}\right)=(1,1.75)$. In contrast, when $e_{j}=2$ the net utility function slopes upward gently from the point $\left(e_{i}, e_{j}\right)=(1,1.75)$ Finally, when $e_{j}=4$ the net utility function slopes upward rapidly from the point $\left(e_{i}, e_{j}\right)=(1,3.75)$. We now proceed to compute the ith individual's best response or reaction function.

\subsection{The Best Response Function}

Some thought and straightforward algebra together tell us that when the $j$ th individual's effort $e_{j}<2$, individual i's best response is to choose $e_{i}=1$. Similarly, we can reason that when the $j$ th individual's effort $e_{j}<4$ individual $i$ 's best response is to choose $e_{i}=5$ which is clearly a corner solution. When the $j$ th individual's effort $e_{j}=2$, the ith individual's best response is obtained by solving

$$
\max _{e_{i} \in[0,5]}\left(2 e_{i}-\frac{e_{i}^{2}}{4}\right) \text {. }
$$

The first order necessary condition for an optimum and the optimal value of $e_{i}$ are

$$
2-e_{i} / 2=0 \Rightarrow e_{i}=4
$$

Given the structure of our problem, we can deduce that as $e_{j}$ increases above 2, the best response of the ith individual will increase above 4 until it eventually hits the corner solution of $e_{i}=5$. In the case where individual $i$ 's best response lies between 4 and 5 , this individual maximizes his or her net utility. This means that (s)he solves

$$
\max _{e_{i}[0,5]}\left(e_{i} \cdot e_{j}-\frac{e_{i}^{2}}{4}\right) \text {. }
$$

Differentiating the maximand in Equation (7), the first order necessary condition for an optimum and the best response function we seek are given by

$$
e_{j}-e_{i} / 2=0 \Rightarrow e_{i}\left(e_{j}\right)=2 e_{j} .
$$

Now observe that for any individual $j$ effort $e_{j} \in[2,2.5]$, the best response of the $i$ ith individual lies in the range [4,5]. Similarly, for any individual $j$ effort $e_{j}>2.5$ the best response of the ith individual is still the corner solution in which effort $e_{i}=5$ Pulling all of the above discussion in section 2.3 together, we infer that individual i's best response function in full generality is

$$
e_{i}\left(e_{j}\right)=\left\{\begin{array}{lll}
1 & \text { if } & e_{j}<2 \\
2 e_{j} & \text { if } & e_{j} \in[2,2.5] \\
5 & \text { if } & e_{j}>2.5
\end{array}\right\} .
$$

Suppose we have two identical pairs of individuals of the sort we have been analyzing thus far in sections 2.2 and 2.3. These two pairs are located in two different nations. In the first (second) nation, arranged marriages are uncommon (common) and therefore it is relatively difficult (straightforward) for the two individuals to apply and coordinate 
effort. In this setting, we want to study the application of effort and an implication of this application by these two pairs of individuals who wish to have an arranged marriage.

\subsection{A Comparison}

To fix ideas, let us think of Sweden as an example of a country where arranged marriages are uncommon and India as a country where arranged marriages are common. Then, it is not surprising that for individuals wishing to have an arranged marriage, effort application and coordination in "arranged marriage unfriendly" Sweden is much more difficult than it is in "arranged marriage friendly" India. Given this state of affairs, we now want to use our theoretical analysis in sections 2.1 to 2.3 to explain whether it is likely that the net utility of the pair wishing to have an arranged marriage in Sweden is much lower than the corresponding net utility of the pair in India.

The discussion in Section 2.3 in general and the best response function in Equation (9) in particular tells us that in the arranged marriage effort application game that we are studying in this note, there are two pure strategy Nash equilibria. In the first Nash equilibrium we have $\left(e_{i}^{*}, e_{j}^{*}\right)=(1,1)$ and in the second Nash equilibrium, we get $\left(e_{i}^{* *}, e_{j}^{* *}\right)=(5,5)$. Straightforward computations tell us that in the first or $\left(e_{i}^{*}, e_{j}^{*}\right)=(1,1)$ Nash equilibrium, the net utility of each of the two individuals wishing to have an arranged marriage is $u_{i}^{*}=1.75$. In contrast, in the second or $\left(e_{i}^{* *}, e_{j}^{* *}\right)=(5,5)$ Nash equilibrium, the corresponding net utility to the two individuals is $u_{i}^{* *}=18.75$.

So, our analysis shows that it is certainly likely that in arranged marriage unfriendly Sweden, individuals wishing to have an arranged marriage will obtain net utility that is much lower than the net utility obtained by identical individuals in arranged marriage friendly India. We can think of this result as an example of a situation in which selffulfilling expectations give rise to two equilibria with high and low net utilities to the two relevant pairs of individuals.

In the arranged marriage effort application game that we are analyzing, our analysis thus far shows clearly that the effort application of individual $i$ is increasing in the effort application of individual $j$. In game-theoretic language, this means that the effort application choices of the two individuals are strategic complements. ${ }^{3}$ In fact, it is this complementarity that gives rise to two equilibria with very different net utilities to the two relevant pair of individuals in Sweden and in India. This completes our analysis of the arranged marriage effort application game.

\section{Conclusion}

We shall not repeat our main conclusions from Section 2. Having said this, our principal summary point is that in this note, we analyzed a simple, static game model of the effort applied by two individuals ( 1 and 2 ) who wished to have an arranged marriage. The analysis conducted here can be extended in a variety of ways. Here are two suggestions for possible extensions. First, it would be useful to study a dynamic game model in which the two individuals are interested not only in applying effort to bring an arranged marriage to fruition but also in applying effort to ensure that the arranged mar-

${ }^{3}$ See Tadelis ([17], p. 93) for a textbook description of strategic complements and substitutes. 
riage does not end in divorce at some future date. Second, following the work of Greenberg et al. [18], it would also be instructive to study the insights that can be gained by viewing the process of arranging marriages as a matching problem. Studies that examine these aspects of the problem will shed valuable light on the functioning of arranged marriages.

\section{Acknowledgements}

We thank an anonymous reviewer for helpful comments on a previous version of this paper. In addition, Batabyal acknowledges financial support from the Gosnell endowment at RIT and he thanks Cassandra Shellman for her assistance in formatting the paper. The usual disclaimer applies.

\section{References}

[1] Becker, G.S. (1973) A Theory of Marriage: Part I. Journal of Political Economy, 81, 813-846. https://doi.org/10.1086/260084

[2] Manser, M. and Brown, M. (1980) Marriage and Household Decision-Making: A Bargaining Analysis. International Economic Review, 21, 31-44. https://doi.org/10.2307/2526238

[3] Peters, H.E. (1986) Marriage and Divorce: Informational Constraints and Private Contracting. American Economic Review, 76, 437-454.

[4] Cornelius, T.J. (2003) A Search Model of Marriage and Divorce. Review of Economic Dynamics, 6, 135-155. https://doi.org/10.1016/S1094-2025(02)00012-1

[5] Vaillant, N.G. and Harrant, V. (2008) Determinants of the Likelihood of Finding the Right Partner in an Arranged Marriage: Evidence from a French Matchmaking Agency. Journal of Socio-Economics, 37, 657-671. https://doi.org/10.1016/j.socec.2006.12.055

[6] Levine, R., Sato, S., Hashimoto, T. and Verma, J. (1995) Love and Marriage in Eleven Cultures. Journal of Cross-Cultural Psychology, 26, 554-571. https://doi.org/10.1177/0022022195265007

[7] Kumar, P. and Dhyani, J. (1996) Marital Adjustment: A Study of Some Related Factors. Indian Journal of Clinical Psychology, 23, 112-116.

[8] Batabyal, A.A. (1998) Aspects of Arranged Marriages and the Theory of Markov Decision Processes. Theory and Decision, 45, 241-253. https://doi.org/10.1023/A:1004998730922

[9] Batabyal, A.A. (2003) On Decision Making in Arranged Marriages with a Stochastic Reservation Quality Level. Applied Mathematics Letters, 16, 933-937. https://doi.org/10.1016/S0893-9659(03)90019-X

[10] Batabyal, A.A. (2005) A Game Model of Dowry Determination in an Arranged Marriage Context. Economics Bulletin, 10, 1-8.

[11] Liu, X. (2007) Optimal Dynamic Path of Effort on Marriage: Differences between Arranged and Love Marriages. Applied Economics Letters, 14, 49-52. https://doi.org/10.1080/13504850500425691

[12] Batabyal, A.A. and Beladi, H. (2011) A Stochastic Dynamic Programming Approach to Decision Making in Arranged Marriages. Applied Mathematics Letters, 24, 2197-2200. https://doi.org/10.1016/j.aml.2011.06.025

[13] Batabyal, A.A. (2016) Making an Arranged Marriage Work: A Game-Theoretic Analysis. Theoretical Economics Letters, 6, 416-419. https://doi.org/10.4236/tel.2016.63046

[14] Uberoi, P. (2006) Freedom and Destiny. Oxford University Press, Oxford, UK.

[15] Lee, J.H. (2013) Modern Lessons from Arranged Marriages. New York Times, January 18. 
[16] Ravindra, G. (2015) Shaadi Remix. Wheatmark Paublishing, Tucson, Arizona.

[17] Tadelis, S. (2013) Game Theory. Princeton University Press, Princeton, New Jersey.

[18] Greenberg, J., Luo, X., Oladi, R. and Shitovitz, B. (2002) (Sophisticated) Stable Sets in Exchange Economies. Games and Economic Behavior, 39, 54-70.

https://doi.org/10.1006/game.2001.0890

\section{Submit or recommend next manuscript to SCIRP and we will provide best service} for you:

Accepting pre-submission inquiries through Email, Facebook, LinkedIn, Twitter, etc. A wide selection of journals (inclusive of 9 subjects, more than 200 journals)

Providing 24-hour high-quality service

User-friendly online submission system

Fair and swift peer-review system

Efficient typesetting and proofreading procedure

Display of the result of downloads and visits, as well as the number of cited articles

Maximum dissemination of your research work

Submit your manuscript at: http://papersubmission.scirp.org/

Or contact tel@scirp.org 